\title{
Bioactive Macrocyclic Peptides and Peptide Mimics
}

Rob M.J. Liskamp, Dirk T.S. Rijkers, and Saskia E. Bakker

\section{1}

\section{Introduction}

The number of both naturally occurring and synthesized biologically active cyclic peptides, modified peptides, and peptide mimics is rapidly increasing. So far, many of these sometimes biologically very potent peptides have unfortunately unknown molecular targets or mechanisms of action. This certainly opens up very interesting and challenging research areas with respect to uncovering these targets and/or molecular mechanisms of biological activity, which - depending on the biological action - can be very promising, for example, for the development of new drugs. However, merely a review of most biologically active cyclic peptides - if this were possible at all - is not the aim of this chapter. Instead, we wish to focus on selected bioactive macrocyclic peptide systems with known molecular peptide or protein targets as well as details about their molecular interaction mechanism. Where possible, we would like to discuss the contribution of the $c y c l i c$ nature of the peptides to the molecular mechanism of interaction and the ensuing biological activity. We will therefore not include cyclic peptides and mimics merely interacting with membrane lipids or cyclic peptides interacting with DNA or RNA. Each of these topics deserves a review on its own, especially in light of the increasing interest in membrane proteins and transcription activators/regulators.

The selection of cyclic peptides interacting with known molecular targets in this chapter is largely determined by their relevance in relation to possible treatments of diseases. In this respect, probably vancomycin and cyclosporin are the most wellknown cyclic peptides containing modified amino acids, which have had a profound influence on the treatment of life-threatening diseases. The vancomycin-related antibiotics [1] are outstanding examples of cyclic peptide systems containing multiple knotted side chains by which almost absolute control over the shape of the molecule is achieved, leading to efficient binding of crucial fragments of the cell-wall precursor of disease-causing bacteria. 
In the larger peptide antibiotic compounds comprising the class of lantibiotics, the shape of the molecule is determined by several cyclic peptides, including two annulated peptide rings, present within one molecule, giving the lantibiotic a unique way to interact with the target molecule lipid II and subsequent pore-forming capabilities in phospholipid membranes [2].

In an increasing number of examples, the diversity of functions and activities of proteins can be reflected in their smaller peptide counterparts, and this is especially prominent in RGD-containing cyclic peptides and peptide mimics derived from the corresponding RGD sequence in proteins. These are capable of interacting with a variety of integrin receptors $\left(\alpha_{\mathrm{V}} \beta_{3}\right.$ and $\left.\alpha_{\mathrm{IIb}} \beta_{3}\right)$ involved in cellular adhesion and migration [3]. As a result, the RGD sequence is, for example, crucial in the construction of (cyclic) peptide compounds used for molecular imaging and treatment of diseases such as cancer and infections.

However, it is good to realize that many biologically relevant cyclic peptides are not derived from or do not correspond to particular peptide sequence(s) in a larger protein molecule. These cyclic peptides are produced by micro-organisms, and although they are macrocyclic structures, they are of course much smaller than proteins. In addition to vancomycin and the lantibiotics mentioned above, other important examples are cyclosporin A [4] and cyclotheonamide [5]. The former cyclic peptide is the widely used immunosuppressive drug while the latter is capable of specifically interacting with thrombin, a crucial serine protease in the blood clotting cascade. As a consequence, cyclotheonamide and chemically synthesized analogs are potentially important for modulating blood clotting.

In principle, there is no limitation to the nature of the biological process or cascade, which can be influenced by (cyclic) peptides and their derivatives, and it should be emphasized that cyclic peptides and mimics derived thereof could be powerful instruments in modulating signal transduction. This is apparent, for example, from the interaction of cyclic peptides with SH2-domains involved in, among others, allergy, cancer and other diseases.

At present many biologically extremely important cyclic peptides and derivatives such as octreotide/octreotate [6] fall outside the scope of this contribution, simply because their exact molecular interaction mechanism together with their biological target are still unknown [7], which certainly poses a challenge for future research directed toward unraveling their biomolecular mechanisms of action. In addition, in many cases the molecular events subsequent to the specific interaction with a receptor are still unknown, leaving many unanswered questions with respect to the ultimate biological effects.

Cyclization of a linear peptide (Figure 1.1) endows the cyclic peptide first of all with a considerably reduced flexibility as compared to the parent peptide, which is (generally consisting of up to about ten amino acid residues) a very flexible molecule. Each amino acid residue contributes two single bonds to the conformational flexibility of the molecule, and generally speaking the only relatively rigid bond (trans and trans/cis in proline and $\mathrm{N}$-alkylated amino acid-containing peptides) is the amide bond. After approximately ten to twenty amino acid residues, secondary structure elements (such as $\alpha$-helices [8], turns, and $\beta$-strands) start to form. The reduced 

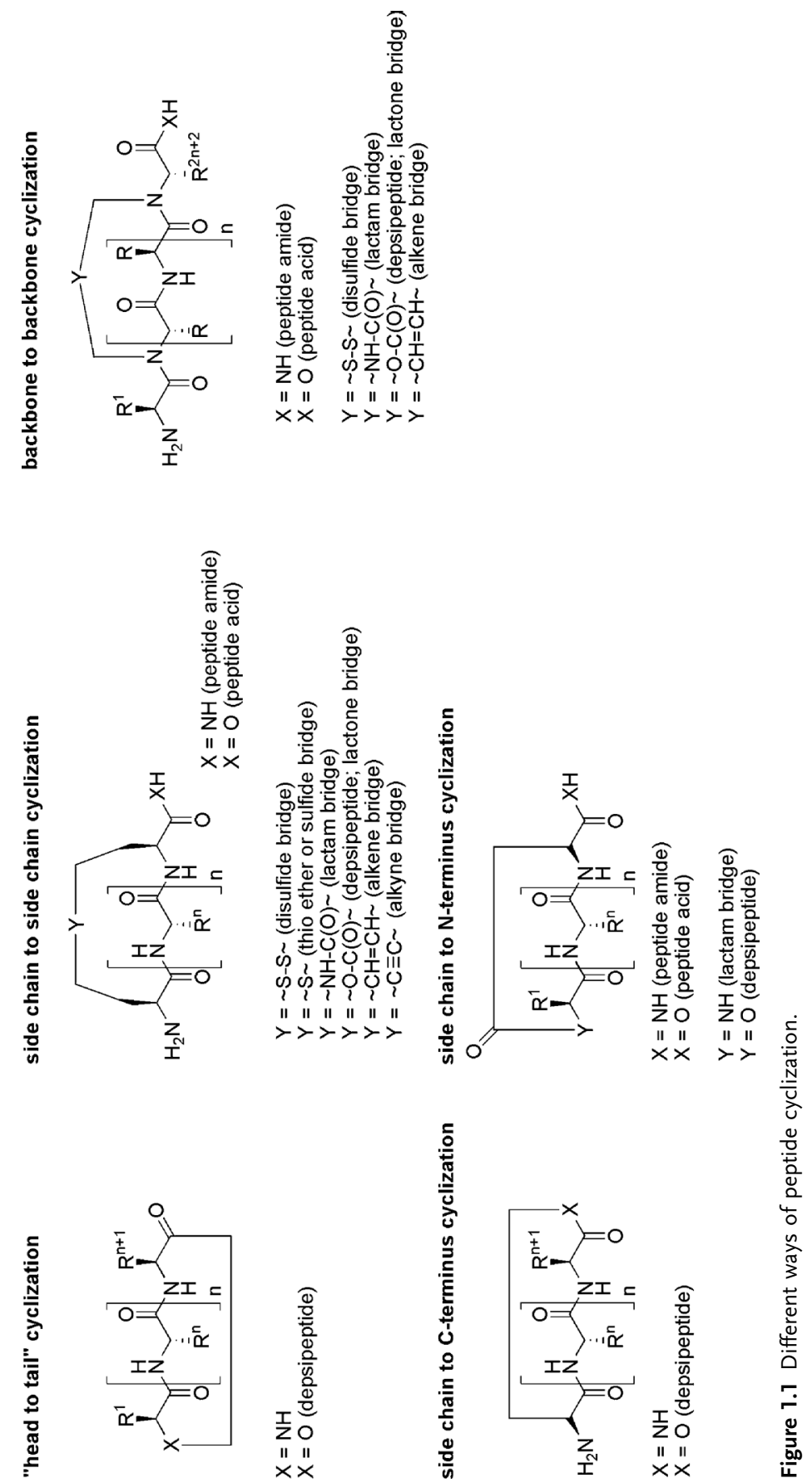
flexibility of the cyclic peptide derivative as compared to the open form is a distinct advantage for interaction with a potential molecular target. In general, provided that no significant enthalpy-entropy compensation takes place [9], a cyclized peptide which is less flexible and therefore more pre-organized, will display a higher affinity because it will lose less entropy upon interaction with its molecular target. As such, cyclization is also a universal first approach to increase the affinity of a peptide. An associated advantage of a cyclic peptide structure is the decreased sensitivity to proteolytic degradation, especially by exoproteases, which will be favorable for the half-life of the (cyclic) peptide and thereby its bioavailability.

1.2

\section{Selected Cyclic Peptides}

For this review we have selected the cyclic modified peptides mentioned above, i.e. vancomycin, nisin, cyclosporin, and cyclotheonamide, as well as two examples, i.e. RGD-containing cyclic peptides and SH2 domain binding cyclic peptides, which were inspired by proteins.

\subsection{1}

\section{Vancomycin}

Vancomycin (1, Figures 1.2 and 1.3) is a glycopeptide antibiotic with high activity against Gram-positive bacteria and is particularly renowned for its activity against the feared methicillin-resistant Staphylococcus aureus (MRSA) species [1b]. Vancomycin is produced by Amycolatopsis orientalis, a bacterium originally found in a soil

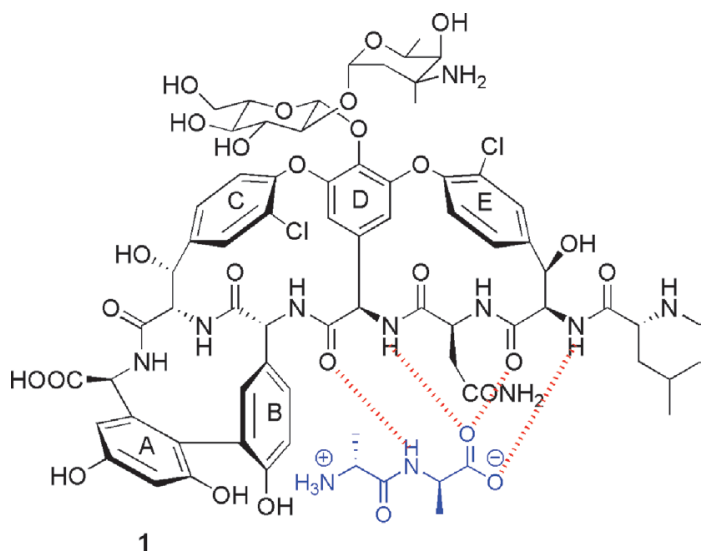

Figure 1.2 Structure of vancomycin (1). The dipeptide ligand DAla-D-Ala is shown in blue and the hydrogen bonds are shown in red. In the case of the D-Ala-D-lactate ligand, one hydrogen bond is lost and replaced by a repulsion due to the free electron pairs on oxygen. 

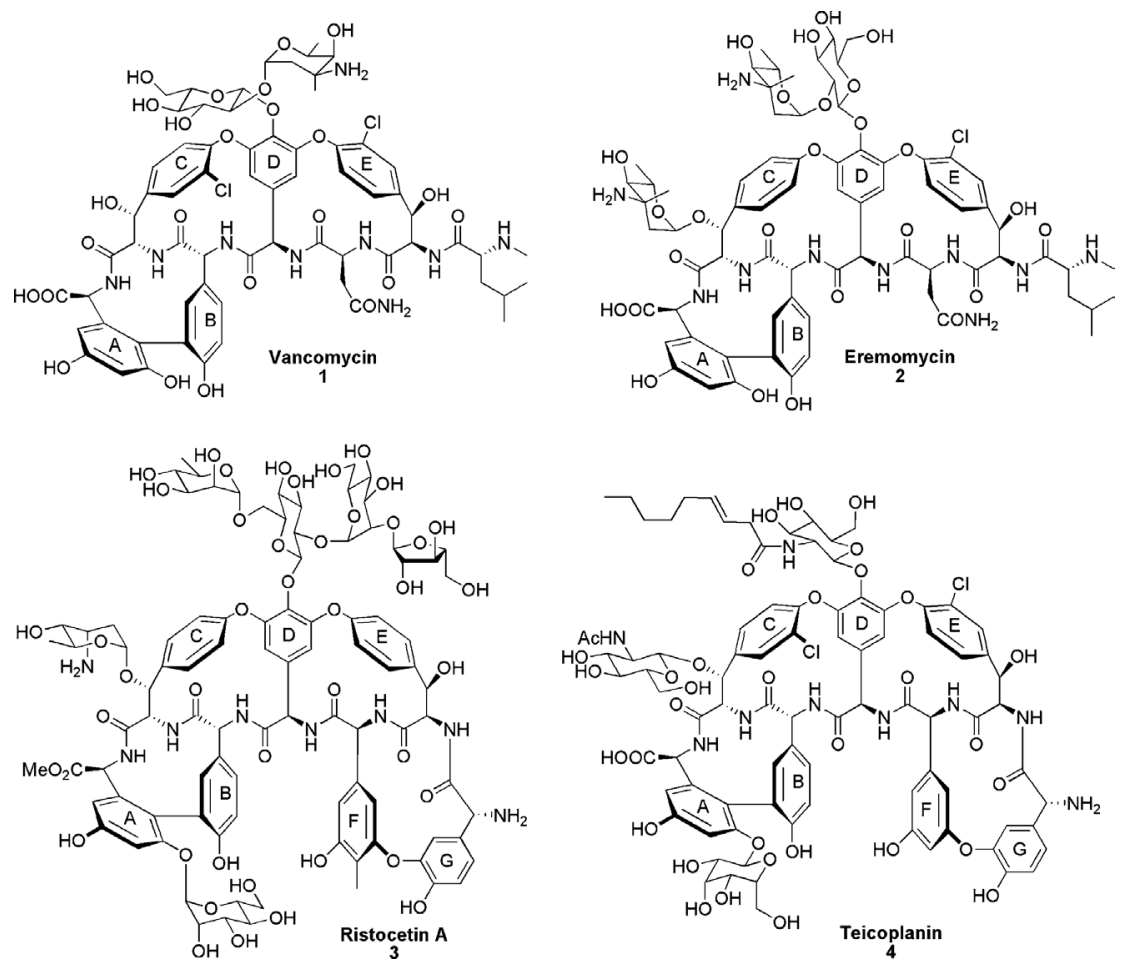

Figure 1.3 Chemical structures of glycopeptides antibiotics vancomycin (1) [1], eremomycin (2) [15a], ristocetin A (3) [15b], and teicoplanin (4) [15c].

sample from Borneo, Indonesia. The biosynthetic pathway and the total syntheses of vancomycin and related structures have been reviewed in a comprehensive account by Nicolaou and coworkers [1b]. Vancomycin is one of the representatives of the glycopeptide family [1]. The vancomycin aglycon consists of a heptapeptide with several non-proteinogenic amino acids. Residues 4,5 , and 7 are phenylglycine derivatives with different substitution patterns of the aromatic ring, while residues 2 and 6 are $\beta$-hydroxytyrosines with chlorine substituents in the ortho position. The side chains are involved in the formation of three macrocycles named after the component residues: residues 5 and 7 form the $A$ - $B$ biaryl system, while residues 2,4 , and 6 form the two bisaryl ether systems $C$ - $D$ and $D$-E, respectively (Figures 1.2 and 1.3). The sugar moieties are glucose and vancosamine [1b].

Vancomycin and other glycopeptides inhibit cell wall synthesis by non-covalent binding to the D-Ala-D-Ala peptide motif of the cell wall precursor lipid II [10]. Four hydrogen bonds are formed when vancomycin binds the D-Ala-D-Ala motif, and all of these involve the peptide backbone [1,10], as shown in Figure 1.2.

Dimerization of vancomycin and other glycopeptide antibiotics, as well as anchoring of glycopeptides in the bacterial cell membrane, contribute favorably to the 
antibacterial effect [1]. Although eremomycin (2, Figure 1.3) has a lower affinity for model peptides in vitro, in vivo it is consistently more active than vancomycin. It seems that the actual activity of glycopeptide antibiotics depends on a balance between the dimerization constant and the affinity for model peptides in vitro [11]. The dimerization constant increases when ligand is added and vice versa [12], except in the case of ristocetin A [11] (3, Figure 1.3). Anchoring of the antibiotic to the bacterial cell wall by a lipophilic chain, as is the case with teicoplanin (4, Figure 1.3), also enhances antibacterial activity [13]. In both cases the enhanced activity can be explained by a decrease in entropy of binding, because the binding of the antibiotic to the target peptide becomes effectively intramolecular $[1,12,13]$. Cell wall synthesis may be inhibited because the enzymes involved in this can no longer bind to the peptide [10].

Resistance to vancomycin can follow three patterns [14]. In both VanA- and VanBtype resistance, the terminal D-alanine residue of the peptidoglycan cell wall precursor is replaced by a D-lactate. Because this changes the amide bond into an ester, a hydrogen bond donor is lost and repulsion between the carbonyl oxygen and lactateester oxygen is present, resulting in a thousand-fold loss of affinity (Figure 1.2). The VanA Enterococci (E. faecium, E. faecalis) are resistant to high concentrations of vancomycin and also clinically used teicoplanin (4), whereas VanB Enterococci are resistant to a wider range of vancomycin concentrations but remain susceptible to teicoplanin [14]. In VanC-type resistance (E. gallinarum, E. casseliflavus), the terminal amino acid D-alanine is replaced by D-serine, and loss of activity is probably due to steric hindrance from the serine side chain $[1,14]$. Knowing the molecular nature of resistance may be very important for the development of new antibiotics to fight resistant micro-organisms.

Although the total syntheses of vancomycin and derivatives can be heralded as top achievements in organic synthesis [1], they are of course not practical for obtaining these compounds for application purposes. Therefore, there has been considerable interest in the preparation of simplified mimics of vancomycin, having especially (part of) the binding cavity for D-Ala-D-Ala.

With respect to this, Ellman and coworkers [16], Zhu and coworkers [17], Arnusch and Pieters [18], and Liskamp and coworkers [19] have prepared (monocyclic) mimics of the $D$-E part of the cavity of these antibiotics via an intramolecular nucleophilic aromatic substitution [16-18] or a Sonogashira-based macrocyclization [19] (Figure 1.4). Recently, a bicyclic mimic of the $C-D-E$ cavity, which was prepared by a Stille reaction followed by tandem ring-closing metathesis (9, Figure 1.4$)$, was described by Liskamp and coworkers [20]. Considerable challenges lie ahead for the synthetic chemist in order to develop practical syntheses of mimics of vancomycin capable of binding not only D-Ala-D-Ala, but also cell wall parts of resistant bacteria, i.e. D-Ala-D-lactate.

\section{2 .2}

\section{Lantibiotic: Nisin}

Nisin is a peptide-based antibiotic from the lantibiotic (lanthionine-containing antibiotic) family [2]. It is produced by certain strains of Lactococcus lactis and is active 
1.2 Selected Cyclic Peptides
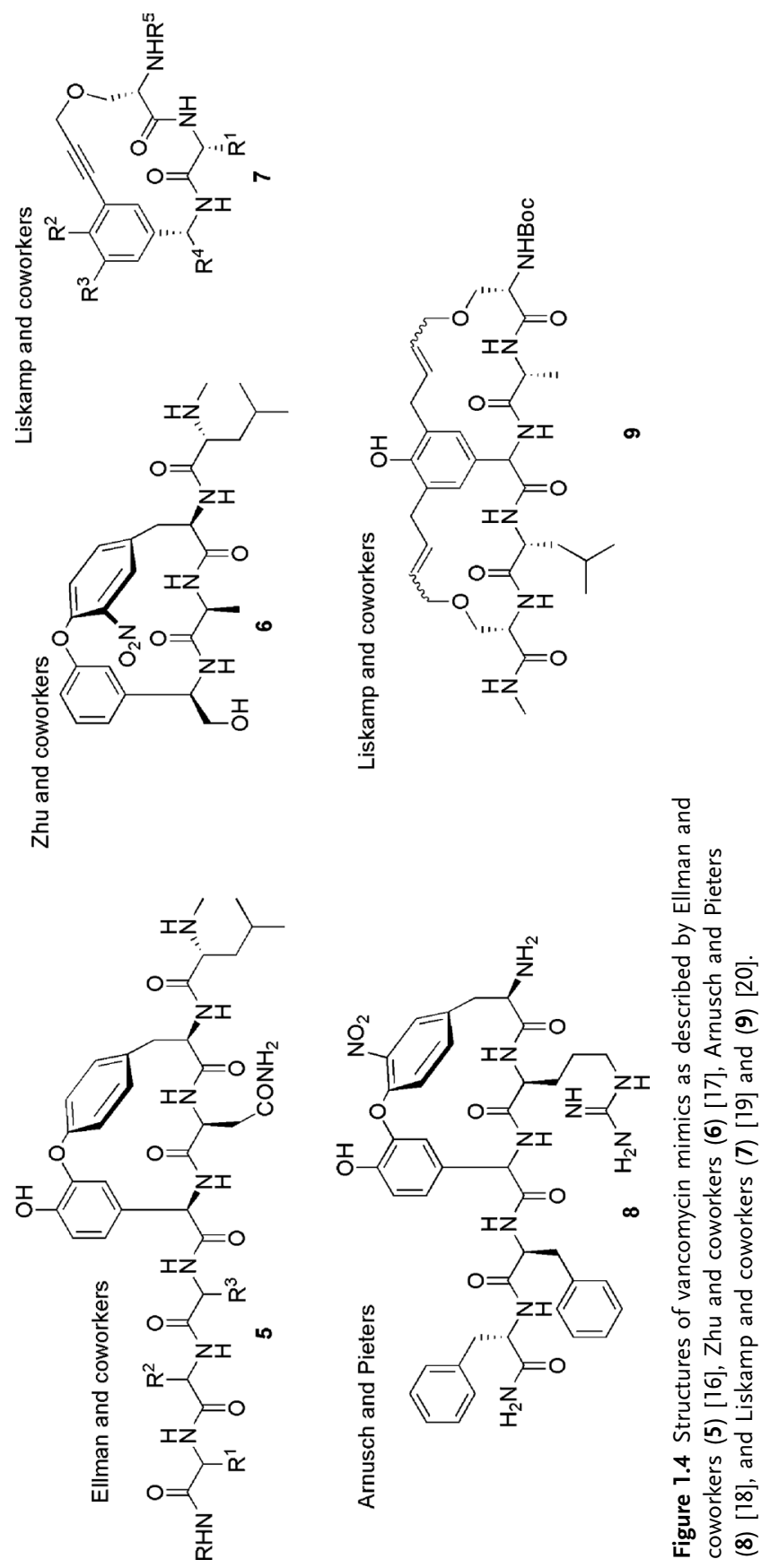
A

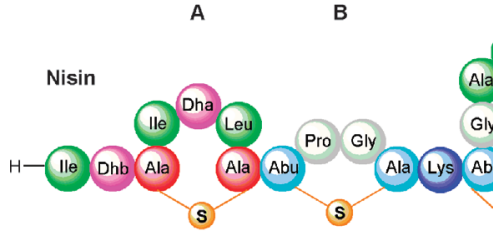

$\mathrm{C}$

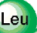

D $\quad$ E

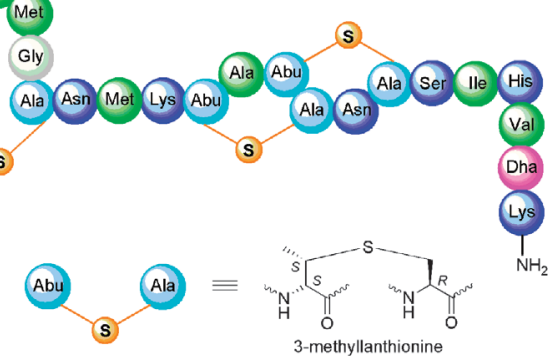<smiles>C#CNC(=O)C(C)=O</smiles>

(Z)-dehydrobutyrine dehydroalanine

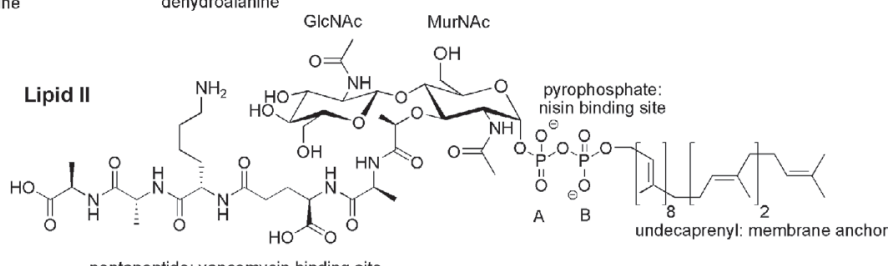

Figure 1.5 Representation of the structure of nisin. Hydrophobic amino acid residues are shown in green, polar residues in blue, and unsaturated amino acids in purple. The lanthionine ring is shown in red and the 3-methyllanthionine rings in turquoise.
The structural formulas of lanthionine, 3-methyllanthionine, dehydroalanine, and $(Z)$-dehydrobutyrine are also shown. The chemical structure of lipid II is shown, and the binding sites of vancomycin and nisin are indicated.

against most Gram-positive bacteria. Its antimicrobial effect has been long known, and nisin has been used as a food preservative for over 30 years. Its structure [21] is characterized by several connected cyclic peptides, including an annulated cyclic peptide system, providing the peptide with a unique shape (or shapes) which could not have been achieved by the corresponding linear sequences (Figure 1.5). Like other antimicrobial peptides, e.g., magainin, nisin has a net positive charge and an amphiphatic character. In addition to the cyclic peptide structures that are so characteristic for the lantibiotics, it contains the unusual amino acids lanthionine and 3-methyllanthionine as well as the unsaturated amino acids dehydroalanine and (Z)-dehydrobutyrine (Figure 1.5).

In 1960, Ramseier [22] discovered that nisin causes leakage of intracellular molecules from cells. Later, it was shown that it disturbs the membrane potential and interferes with energy transduction [23]. In addition, it causes inhibition of biosynthesis of the cell wall processes by blocking the synthesis of peptidoglycans [24] and by binding to the precursor lipid II [25]. However, micromolar amounts of nisin are needed to permeate artificial membranes [26,27] or to inhibit cell wall synthesis in vitro [28], while the in vivo activity of nisin is in the nanomolar range. As vancomycin, which binds to the peptide motif in lipid II, inhibited the antibacterial activity and 


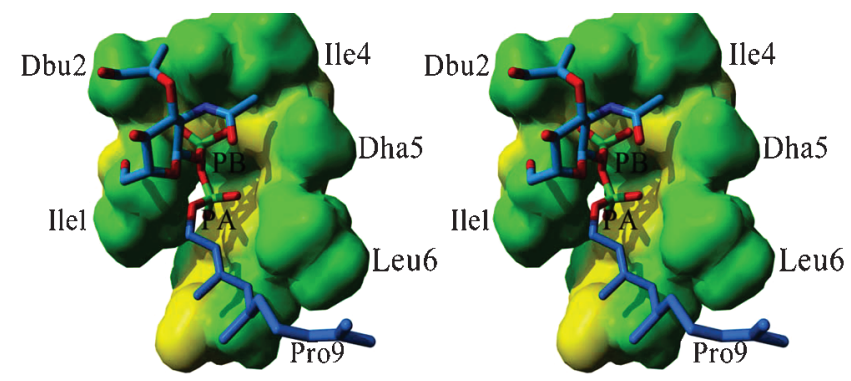

Figure 1.6 The pyrophosphate cage structure of nisin bound to lipid II. Side chains of nisin are depicted in green, backbone in yellow. Lipid II is depicted in blue [PDB entry code: IWCO [32], molecular graphics created with YASARA (www.yasara.org) and PovRay (www.povray.org)].

membrane leakage by nisin in intact cells, Breukink et al. [26] concluded that lipid II is necessary for a high specific nisin activity and resulting pore formation. Studies with artificial membranes containing lipid II confirmed this conclusion [26].

The N-terminal fragment of nisin (1-12) has been shown to act as a nisin antagonist [29]. Mutation data have shown that changes in the N-terminal fragment reduced nisin activity [30]. NMR data showed that solvent accessibility of the A, B, and $\mathrm{C}$ rings of nisin decreased when it bound lipid II [31]. These data independently led to the conclusion that the N-terminal fragment of nisin, notably the ring structure $\mathrm{A}$ to $\mathrm{C}$, is involved in lipid II binding. This was confirmed when the NMR structure of the nisin-lipid II complex was determined [32]. Rings A and B of nisin form a cagelike structure around the pyrophosphate moiety of lipid II. This structure shows that hydrogen bonds are formed between backbone amides of nisin and phosphate oxygens, while side chain interactions are of only minor importance. Only leucine residue six is conserved as a hydrophobic residue and interacts with the prenyl chain of lipid II (Figure 1.6).

In a model for pore formation, Hsu et al. proposed that after initial binding of nisin to the lipid II pyrophosphate, the C-ring embeds in the membrane, followed by a turn around the flexible hinge region and insertion of the C-terminus [31]. The size of these pores was calculated to be about $2 \mathrm{~nm}$ [33]. Studies with pyrene-labeled lipid II enabled Hasper et al. to calculate that a single nisin-lipid II pore consists of four lipid II molecules and eight nisin molecules (Figure 1.7). The pores are highly stable, even on addition of detergents that cause disruption of membranes [34].

Other lantibiotics that do not have the ability to form pores and indeed do not cause cell leakage have nevertheless still an impressive antibacterial effect in vivo. With respect to this, an alternative mechanism of antibacterial activity was recently described by which members of the lantibiotic family kill Gram-positive bacteria by binding lipid II and removing it from the cell division site (or septum) and thus block cell wall synthesis [35].

The cyclic peptide systems in nisin can be considered as side chain-cyclized peptide derivatives. However, they do not contain disulfide bridges, which is the most common 


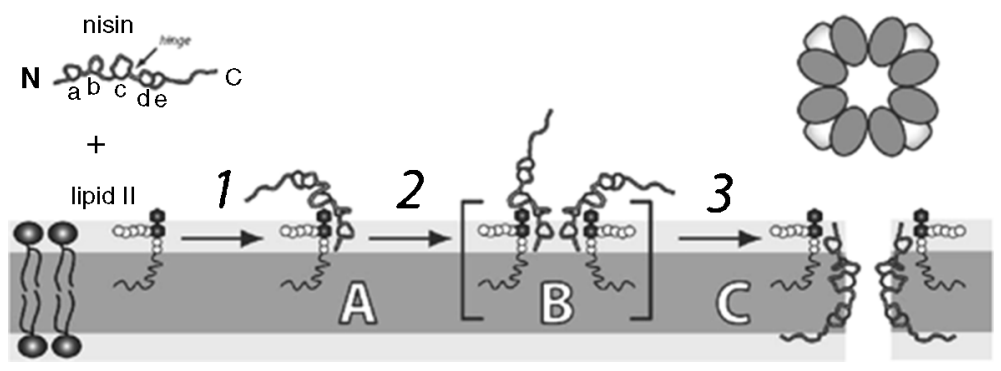

Figure 1.7 Interaction of nisin with phospholipid model membranes: mechanism of pore formation (reprinted with permission from Ref. [34]. Copyright 2007 (C) American Chemical Society).

way of generating side chain-cyclized peptides. In contrast they have sulfide or thioether bridges as part of their ring structures, which are introduced biosynthetically by posttranslational modification. This rather unusual cyclization moiety enticed us to start investigating whether also "bridges" other than thioether bridges could be introduced as cyclization elements for obtaining mimics of the nisin ring structures [36]. Attention was directed towards designing and synthesizing alkene, alkyne, and alkane mimics of the thioether bridge, using ring-closing alkene and alkyne metathesis, sometimes followed by hydrogenation. Thus mimics of the $A(\mathbf{1 0}, \mathbf{1 1}$, and 14), $\mathrm{AB}$ (12), C, and D/E (16) ring systems were prepared (Scheme 1.1). Apparently, the backbone structure of the D/E ring system has a predisposition towards a knotted ring structure, since it was possible to obtain an alkene mimic (16) directly in good yield (95\%) from a double ring closing metathesis reaction of the tetra-allylglycine containing linear precursor (15) in a single reaction step [36d] (Scheme 1.1).

Based on the pyrophosphate cage structure of nisin bound to lipid II, a tricyclic mimic was designed and synthesized in which a lactam bridge connects the B-ring mimic with the A-ring mimic. The biological activity data are very promising and justify further improvement of the designed lipid II pyrophosphate binders. The inherent flexibility of a peptide, even when it is cyclized, challenges us to control its shape by alternative constraints to those already present.

\section{2 .3}

\section{Cyclosporin A}

Cyclosporin was isolated from the fungus Tolypocladium inflatum. Its immunosuppressive activity was discovered in 1976 [4]. Although since then many analogs have been prepared and investigated, cyclosporin A (CsA, Sandimmune, 17) remains the most effective cyclic peptide and is the major immunosuppressant drug to prevent graft rejection after transplant surgery.

CsA is a cyclic undecapeptide consisting completely of hydrophobic amino acids, as shown in Figure 1.8 [37]. Additional structural features are a threonine-derived butenyl-containing amino acid derivative as well as six $\mathrm{N}$-methylated amino acid residues. In addition to reducing the proteolytic degradation rate and increasing the 
1.2 Selected Cyclic Peptides $\mid 11$

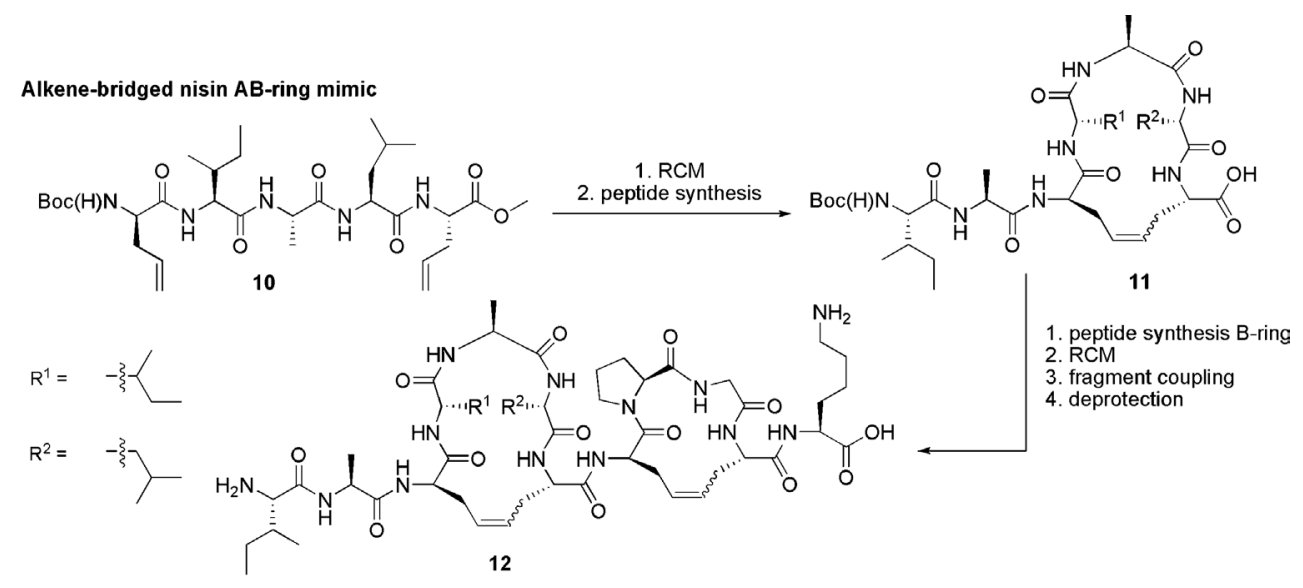

Alkyne-bridged nisin A-ring mimic

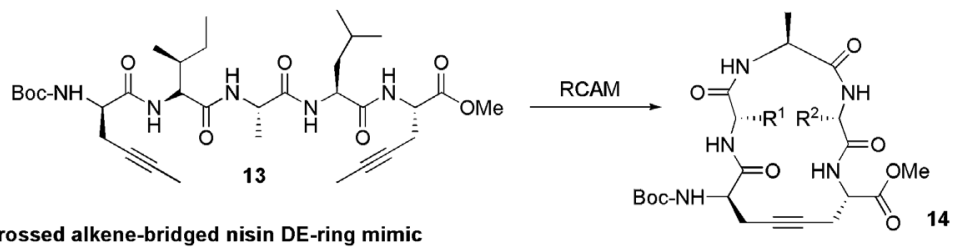

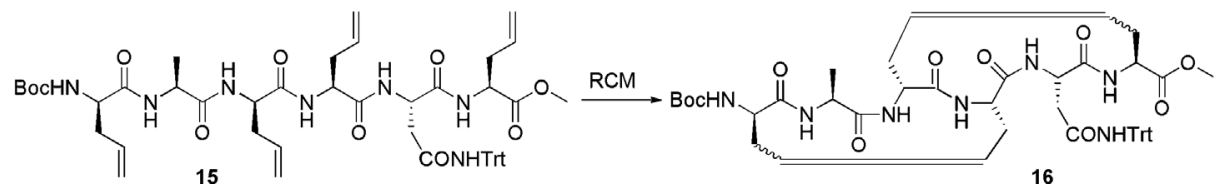

Scheme 1.1 Synthesis and structures of alkane- and alkyne-bridged nisin mimics [36].

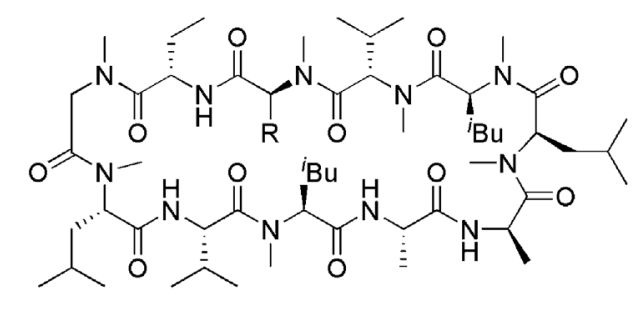<smiles>[R]=C/C=C\C[C@H](C)[C@H](C)O</smiles>

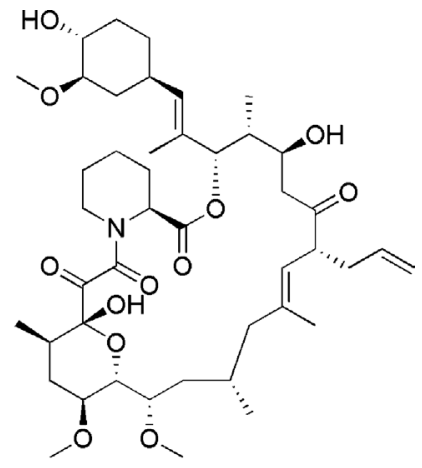

Figure 1.8 Structural formulas of cyclosporin A and FK506. 
hydrophobicity, the influence of these $\mathrm{N}$-methylated residues on the flexibility of the cyclic peptide system could be interesting.

The molecular basis of CsA's biological activity is the formation of a complex with the immunophilin cyclophilin A (CyPA) in such a way that the CsA-CyPA complex can associate with calcineurin (CN), which is a $\mathrm{Ca}^{2+} /$ calmodulin-dependent Ser/Thr phosphatase. As a result, dephosphorylation of a nuclear factor of activated T-cells (NFAT) is inhibited.

X-ray structures [38] of the CsA-CyPA complex show that one side of the CsA ring, comprising the residues 1-3 and 9-11, fits into a groove on CyPA, leaving the opposite side free to interact with $\mathrm{CN}$. Interestingly, CyPA is a cis-trans proline isomerase, but this enzymatic activity does not play a role in $\mathrm{CN}$ inhibition. It seems that $\mathrm{CsA}$ interacts with CyPA to create a larger complex capable of interacting with CN. X-ray structures of the CsA-CyPA-CN complexes (Figure 1.9) show that the conformation of the CsA backbone and the side chains interacting with CyPA in this ternary complex are very similar to those in the binary CsA-CyPA complex. However, the side chains of the CNbinding moiety of CsA have undergone significant conformational changes.

CsA as well as FK506 (18), a completely unrelated non-peptide natural product with similar activity to CsA, have resisted many efforts to improve them as drugs. However, the X-ray structures of the ternary complex may help to stimulate the design of superior immunosuppressants.

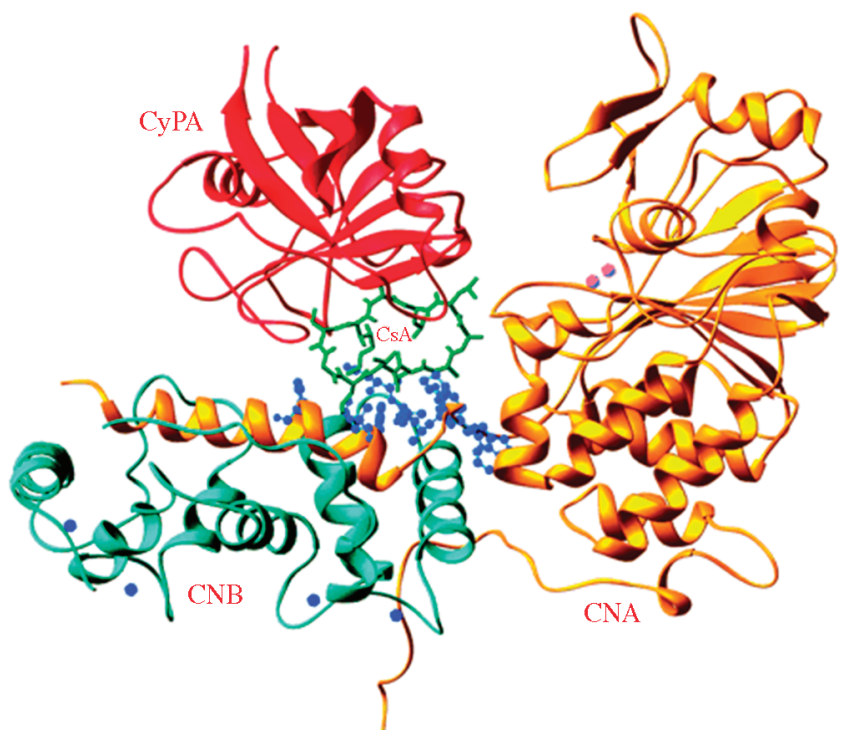

Figure 1.9 Ribbon representation of CyPA-CsA-CN. The catalytic subunit (CNA) of $C N$ is shown in gold, the regulatory subunit (CNB) of CN cyan, cyclosporin (CsA) green, cyclophylin (CyPA) red, the $\mathrm{Zn}^{2+}$ and $\mathrm{Fe}^{3+}$ ions pink, and the $\mathrm{Ca}^{2+}$ ions blue. The residues from $\mathrm{CN}$ involved in binding of CyPA-CsA are shown as a blue ball-stick representation (reprinted with permission from Ref. [38]. Copyright 2007 (C) National Academy of Sciences, USA.) 


\subsection{4}

\section{Cyclotheonamide A and B}

In the early 1990s, Fusetani and Matsunaga isolated two substances from marine sponges of the genus Theonella, which were called cyclotheonamide A and B (CtA 19 and CtB 20, respectively), and were found to be potent inhibitors of various proteinases, especially the blood coagulation enzyme thrombin [5,39]. After structural elucidation by extensive NMR analysis [40], the cyclotheonamides were found to be cyclic pentapeptides having a 19-membered ring and containing a D-phenylalanine (D-Phe), an L-proline (L-Pro), an L-2,3-diaminopropionic acid (L-Dpr) with either a formylated (For, CtA 19) or an acetylated (Ac, CtB 20) $\mathrm{N}^{2}$-amino moiety, a vinylogous L-tyrosine (L-vTyr), and an $\alpha$-ketoarginine (L-kArg) residue (Figure 1.10).

Noteworthy are the presence of the uncommon non-proteinogenic amino acids L- $\alpha$-ketoarginine ( $\alpha$-oxo-L- $\beta$-homoarginine) and vinylogous L-tyrosine (L-tyrosinederived $\alpha, \beta$-unsaturated $\gamma$-amino acid). More important, however, is the presence of the $\alpha$-ketoamide moiety indicating the possible mechanism of action of the cyclotheonamides as potent serine protease inhibitors by serving as an electrophilic trap to form a tetrahedral intermediate (a transition state analog) with the hydroxyl group of Ser195, part of the catalytic triad His57-Asp102-Ser195 of the proteinase.

To obtain insight into the molecular basis of action of the cyclotheonamides and to explain the high affinity as a serine protease inhibitor, complexes of CtA with $\alpha$-thrombin $[41 \mathrm{a}, \mathrm{c}]$ and $\beta$-trypsin $[41 \mathrm{~b}, \mathrm{c}]$, respectively, were studied by X-ray crystallography.

Thrombin is the pivotal trypsin-like protease for the regulation of thrombosis and hemostasis. Thrombin hydrolyzes its natural substrates by recognition of the Pro-Arg motif in the apolar S2- and the primary specificity S1 pocket [42]. The molecular structure of the thrombin-CtA complex (Figure 1.11) showed that CtA was bound to the active site of the enzyme. The arginine side chain formed an electrostatic interaction with Asp189, located at the bottom of the S1 binding pocket.

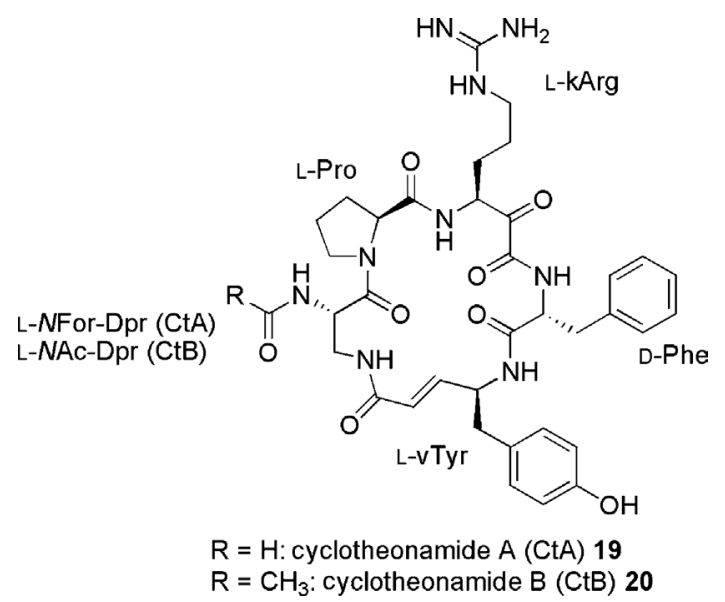

Figure 1.10 Structure of cyclotheonamide A and B. 

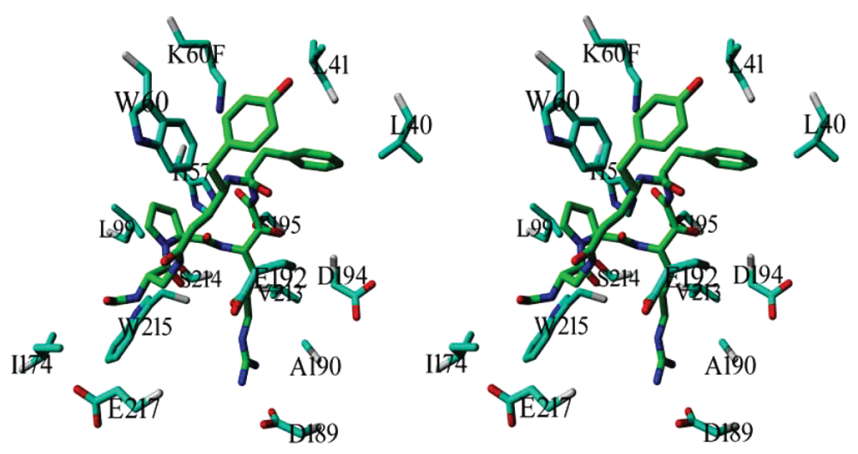

Figure 1.11 Stereoview of CtA 19 bound in the active-site cleft of $\alpha$-thrombin [PDB entry code: 1TMB [41a], molecular graphics created with YASARA (www.yasara.org) and PovRay (www. povray.org)].

Furthermore, the backbone of the Pro-Arg segment formed a hydrogen-bonded antiparallel $\beta$-chain with the Ser214-Gly216 sequence in thrombin.

Both features were highly similar to what was observed for the binding of the highaffinity active site-directed thrombin inhibitor H-D-Phe-Pro-Arg chloromethyl ketone [42]. A well-defined continuous electron density between Ser195 and the carbonyl carbon of the $\alpha$-ketoamide was observed, which was a strong indication of a "covalent complex" through the formation of a tetrahedral hemiketal. The other carbonyl oxygen was involved in a hydrogen-bonding network in the oxyanion hole formed by Gly193 and Ser195. X-ray analysis of the trypsin-CtA complex showed that the gross structural features were similar to thrombin. However, the higher degree of specificity for trypsin $\left(K_{\mathrm{i}} 0.023 \mu M\right.$ versus $\left.0.18 \mu M\right)$ is fairly well explained by the Trp60A-Thr60I insertion loop of thrombin [42], which narrows the active-site binding cleft and thus results in less favorable interaction with the D-Phe and L-vTyr residues.

The interesting macrocyclic pentapeptide scaffold prompted several research groups to design new total synthesis routes for cyclotheonamide [40,41a,b,43] and derivatives thereof [44], mainly for SAR-studies for targeting the development of novel synthetic thrombin inhibitors. The first total synthesis of CtB 20 was published by Hagihara and Schreiber [40]. This synthesis (Scheme 1.2) defined the true stereochemical structure of cyclotheonamide, which had previously been reported incorrectly.

The linear CtB precursor 21 was synthesized from dipeptide Ac-Dpr(Boc)-ProOPac 22, following three amide coupling reactions in the $\mathrm{C} \rightarrow \mathrm{N}$ direction. The vinylogous tyrosine derivative 23 was synthesized from the protected Weinreb amide $\mathbf{2 4}$ that was obtained from the aldehyde intermediate in a Wittig homologation followed by conversion into an active pentafluorophenyl ester. Boc-D-Phe-OH was coupled with BOP/DMAP as the condensing agents. The $\alpha$-hydroxy acid 25 was prepared from the protected arginine Weinreb amide derivative 26. To avoid an intramolecular nucleophilic attack of the guanidinium moiety at the intermediate arginine aldehyde, it was doubly protected with Boc and Mtr groups. Finally, macrolactamization was achieved by a four-step process. Deprotection of the 


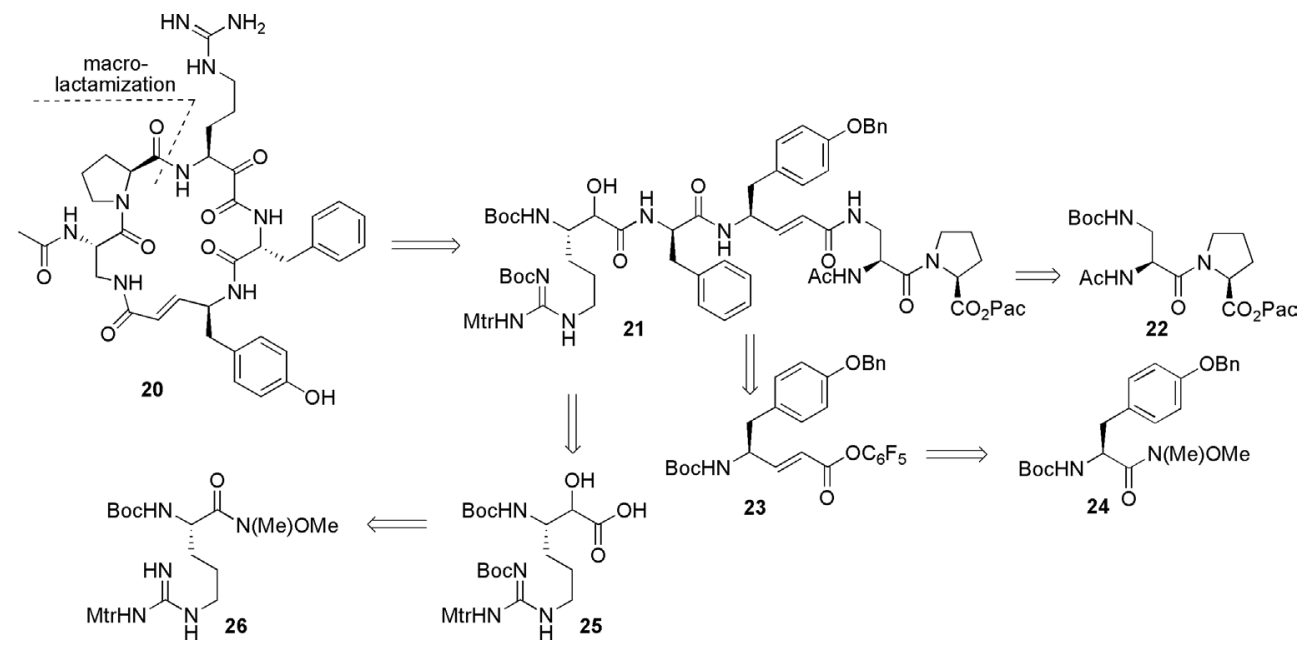

Scheme 1.2 Retrosynthesis of the first total synthesis of CtB 20 as described by Hagihara and Schreiber [40].

phenacyl ester was followed by conversion into the active pentafluorophenyl ester. Then, the N-terminal Boc functionality was selectively removed by $p \mathrm{TsOH}$. Neutralization with DIPEA and treatment with DMAP resulted in a smooth conversion into the protected peptide macrocycle. After oxidation of the hydroxyl functionality, all remaining protecting groups were removed by treatment with TFA in the presence of thioanisole as scavenger to give CtB 20 in 3\% overall yield over 16 reaction steps.

The total synthesis of CtA 19, which was used in the first X-ray studies to elucidate the structure of the CtA $-\alpha$-thrombin complex (Figure 1.11), is shown in Scheme 1.3.

This synthesis, as described by Maryanoff et al. [41a], was based on a convergent $[3+2]$ fragment condensation route (Scheme 1.3). The two segments 28 and 29 were synthesized from their requisite protected amino acid building blocks 30, 31 and 32, 33 respectively. Coupling of $\mathbf{2 8}$ and $\mathbf{2 9}$ to give linear intermediate 27 proceeded in $65 \%$ yield. After selective removal of the $\mathrm{N}$ - and C-terminal protecting groups on 27 , the critical macrocyclization was effected in $65 \%$ yield under high dilution conditions. The intermediate protected macrocycle was then processed in four steps (removal of the phthaloyl functionality and subsequent formylation of the $\alpha$-amino group, Dess-Martin oxidation to the $\alpha$-ketoamide, and finally treatment with HF to remove the tosyl protecting group) to give CtA 19.

Since also many linear peptides that are powerful inhibitors of thrombin [45], have been synthesized it is difficult to evaluate to what extent the cyclic nature of peptide in cyclotheonamide contributes to the activity. Nevertheless, the cyclic nature is advantageous for possible in vivo activity, because of the absence of polar end groups and the greater steric hindrance. With respect to the latter, this can confer greater resistance to degradation by peptidases and enhanced ability to traverse membrane barriers. Unfortunately, cyclotheonamide and congeners have not been further developed into suitable compounds for anticoagulation therapy. 


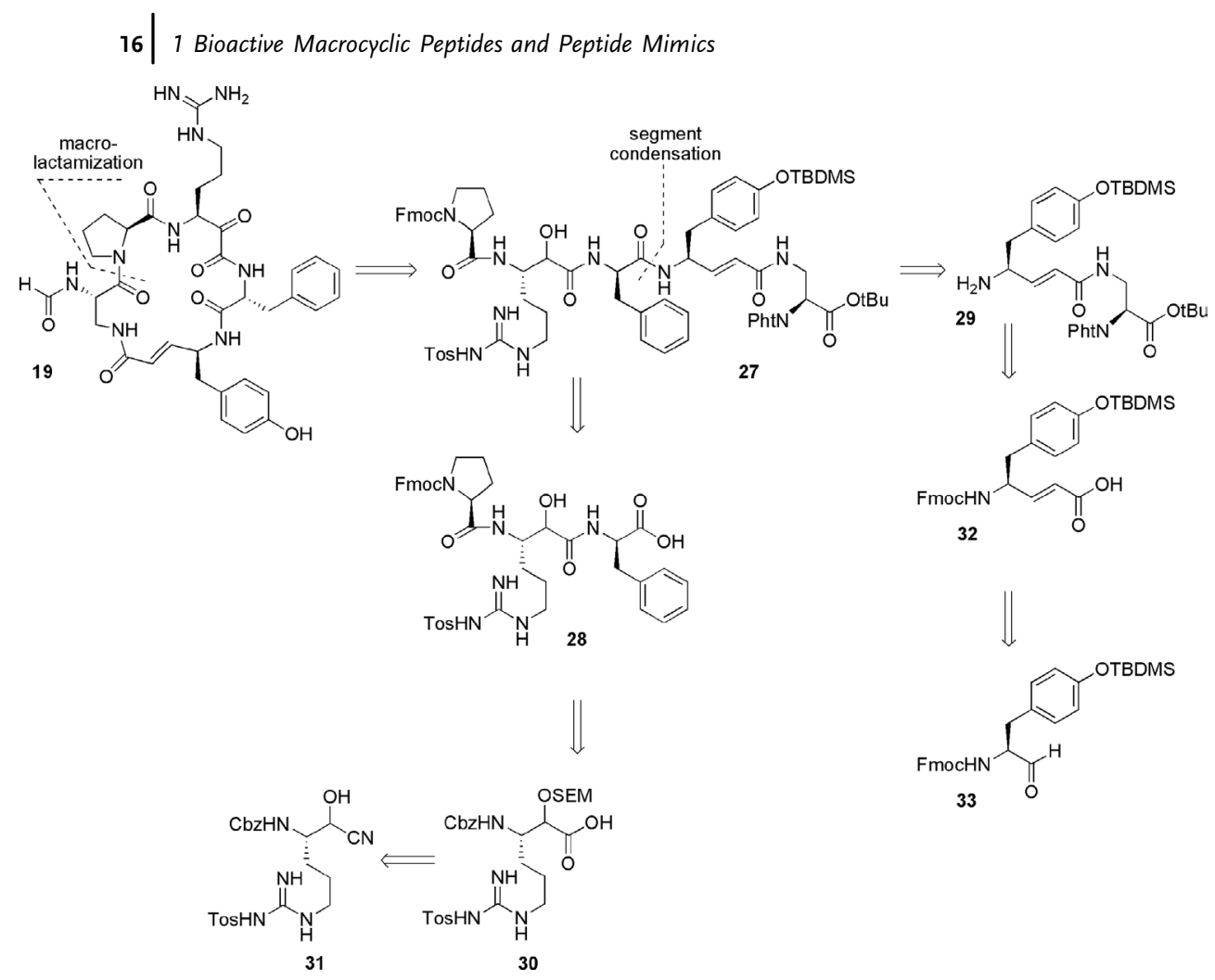

Scheme 1.3 Retrosynthesis of the total synthesis of CtA 19, which was used in the $\mathrm{X}$-ray analysis as a complex with $\alpha$-thrombin [41a].

1.2 .5

cyclo RGD Peptides as $\boldsymbol{\alpha}_{\mathrm{V}} \boldsymbol{\beta}_{3}$ Antagonists

So far, naturally occurring cyclic peptides and mimics thereof have been discussed, in which the cyclic character plays an essential role with respect to affinity and activity in particular. However, this could also be the case for suitable sequences present in proteins, which upon incorporation into macrocyclic peptide structures could lead to molecular constructs with similar or even enhanced affinity and activity without the requirement for the entire protein or a large derivative. This is an exceptional challenge, which could lead to a variety of new biologically active peptides. Although it is a realistic strategy, as is evidenced from the vast number of biologically active cyclic peptides, it may be sometimes a prolonged process and an integral approach featuring an iterative design-synthesis-activity-structure cycle seems to be essential.

Two important examples of cyclic peptides will be highlighted in which amino acid sequences of larger proteins have been successfully used as part of macrocyclic peptide structures to mimic in an almost "pars pro toto" approach important properties of the parent protein. 
Integrins are a class of heterodimeric transmembrane proteins [46] which play an important role in cell signaling, cell-cell adhesion, apoptosis, and cell-matrix interactions [47]. Integrin $\alpha_{\mathrm{V}} \beta_{3}$, which binds to Arg-Gly-Asp (RGD) tripeptide motif-containing ligands [48], plays a pivotal role in tumor angiogenesis and metastasis and is expressed on activated endothelial cells during tumor-induced angiogenesis and on various tumor cell types (e.g., breast, ovarian, and prostate cancers), whereas it is absent on quiescent endothelial cells and normal tissues [47]. Evidence exists that inhibition of $\alpha_{V} \beta_{3}$ integrin function prevents tumor growth and induces tumor regression by antagonizing angiogenesis [49]. Several peptidic [3] and peptidomimetic [50] $\alpha_{\mathrm{V}} \beta_{3}$ antagonists have been synthesized. Among these, the cyclo[Arg-Gly-Asp-D-Phe-Val] (c[RGDfV]) (34), as developed by Kessler and coworkers, is one of the most active and selective antagonists for the $\alpha_{V} \beta_{3}$ integrin [51] (Figure 1.12).

Structure-activity relationship studies on this cyclic pentapeptide showed that the exchange of the valine by a lysine residue (Lys, K) (compound 36) did not significantly influence activity and selectivity [52]. Because the $\varepsilon$-amino moiety of the lysine residue can easily be modified, numerous applications of $c[\mathrm{RGDfK}]$ have been studied for tumor targeting and imaging [53].

The linear precursor of, for example, 34 [51] was obtained by solid-phase peptide synthesis performed on an SASRIN ${ }^{\circledR}$-resin applying the Fmoc/ ${ }^{t} \mathrm{Bu}$ strategy. This allowed the preparation of a protected peptide with both free amino and carboxylic acid termini, which were head-to-tail cyclized using diphenylphosphorylazide, leading to the protected cyclic peptide. Removal of side chain protecting groups afforded 34 .

The structural basis for binding of the prototypical Arg-Gly-Asp sequence to the $\alpha_{V} \beta_{3}$ integrin was recently provided by the crystal structure of 35 complexed with the extracellular segment of integrin $\alpha_{\mathrm{V}} \beta_{3}$ [48] as shown in Figure 1.13.

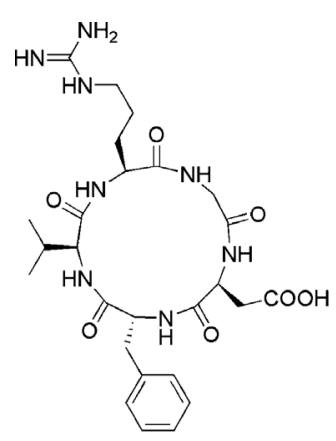

34

cyclo[Arg-Gly-Asp-D-Phe-Val] $c$ [RGDfV]

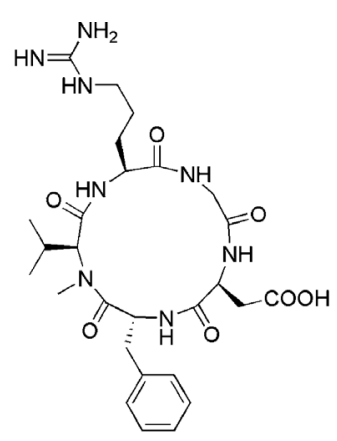

35
cyclo[Arg-Gly-Asp-D-Phe-NMeVal]

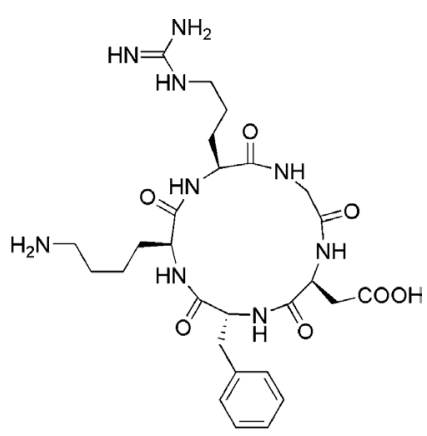

36 cyclo[Arg-Gly-Asp-D-Phe-Lys]

Figure 1.12 Structures of cyclic pentapeptides as potent antagonists of the $\alpha_{v} \beta_{3}$ integrin. 

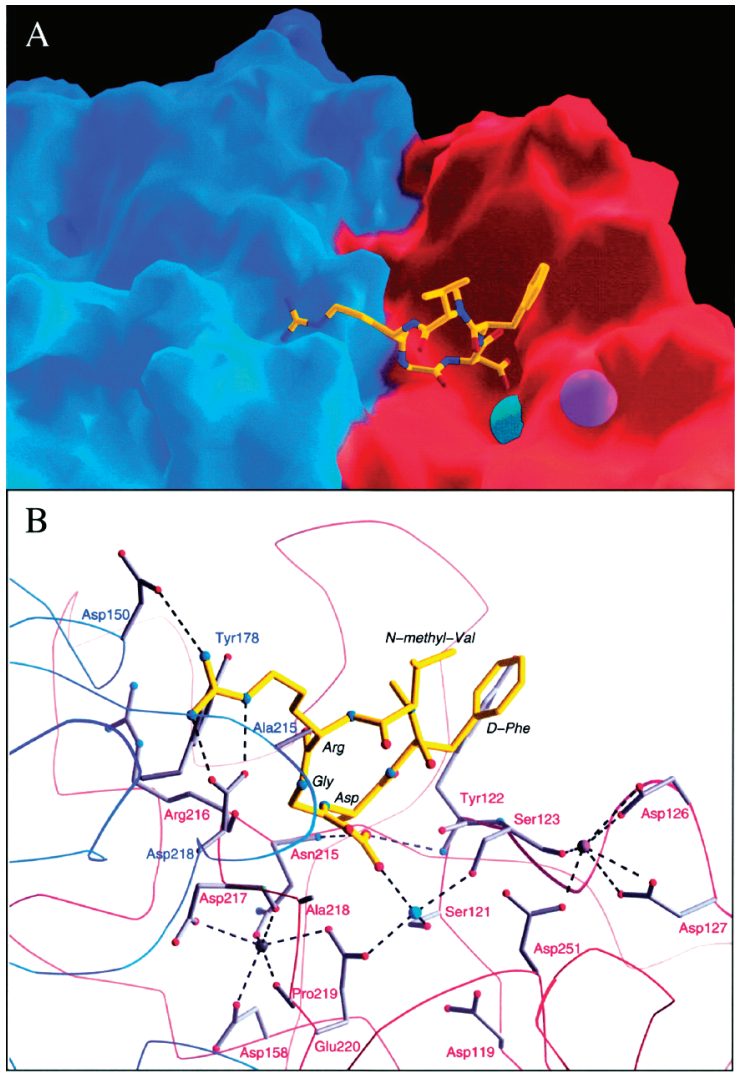

Figure 1.13 The ligand-integrin binding site. (A) Surface representation of the ligandbinding site, with the ligand peptide (35, Fig. 1.12) shown as ball-and-stick model. (B) Interactions between ligand and integrin. The peptide (yellow) and residues interacting with the ligand or with $\mathrm{Mn}^{2+}$ ions are shown in ball-and-stick representation. $\alpha_{V}$ and $\beta_{3}$ residues are labeled blue and red, respectively. Oxygen and nitrogen atoms are in red and blue, respectively. Hydrogen bonds and salt bridges (distance cutoff, $3.5 \AA$ ) are represented with dotted lines (reprinted with permission from Ref. [48]. Copyright 2007 (C) American Association for the Advancement of Science).

The interaction with the Arg-Gly-Asp ligand triggers the structural rearrangements of the $\alpha_{\mathrm{V}} \beta_{3}$ integrin which are necessary for cell signaling pathways. Cyclic RGD peptide 35 binds at the major interface between the $\alpha_{V}$ and $\beta_{3}$ subunits. The arginine side chain inserts into a narrow groove forming a bidentate salt bridge to Asp218 and Asp150. The carboxylate moiety and the aspartic acid residue of 35 form an extensive network of polar interactions with the protein and are completely buried in the complex. The glycine residue undergoes several hydrophobic interactions and lies at the interface between the $\alpha$ and $\beta$ subunits. The other two residues of the cyclic RGD pentapeptide point into the solution and do not have structural interactions with the $\alpha_{V} \beta_{3}$ integrin. Comparison of the X-ray structures of the unbound 
and the RGD-bound $\alpha_{\mathrm{V}} \beta_{3}$ integrin revealed many conformational rearrangements within the protein which may form a structural basis for receptor activation. The backbone conformation of the Arg-Gly-Asp tripeptide motif in the pentapeptide is almost identical to that of the RGD sequence in the natural ligand Echistatin, which is a 49 amino acid protein isolated from the venom of Echis carinatus and is one of the smallest natural ligands that interacts with integrin-type receptors through an Arg-Gly-Asp sequence [54]. This suggests that this X-ray structure [48] (Figure 1.13) may provide a basis for obtaining insight into the molecular interaction details of integrins with other and larger RGD-containing ligands.

\section{2 .6}

\section{SH2 Domain-Binding Peptides}

The class of Src homology 2 (SH2) domains is the largest class of phosphotyrosinerecognizing protein domains. They occur in different protein groups that are mostly involved in signaling and regulation, and thus perform several functions within the cell [55]. Mutations in SH2 domains are implicated in many human diseases, of which a complete overview is given by Liu et al. [55a]. The SH2 domains are approximately 100 amino acids in size and have a well-defined structure, consisting of a central antiparallel $\beta$-sheet and two flanking $\alpha$-helices, followed by a second, two-strand sheet, as elucidated by X-ray crystallography and NMR spectroscopy (Figure 1.14) [56,57].

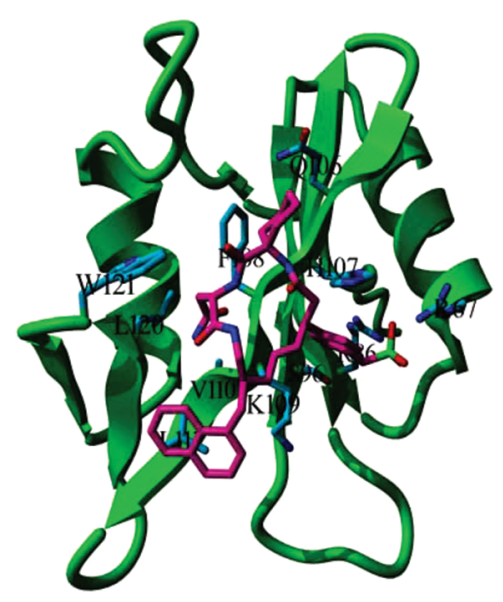

Figure 1.14 NMR-structure of the Grb2-SH2 domain in complex with inhibitor 39. A central antiparallel $\beta$-sheet in the protein is flanked by two $\alpha$-helices, with peptide binding mediated by the sheet, intervening loops, and one of the helices. The specific recognition of phosphotyrosine involves cation- $\pi$ interactions between

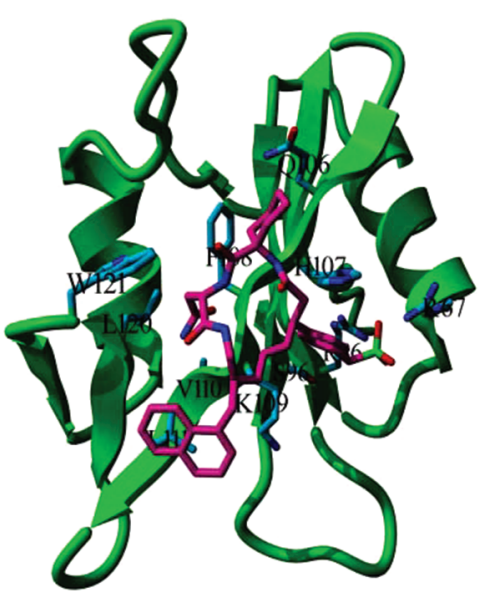

lysine and arginine side chains and the aromatic tyrosine side chain, in addition to hydrogen-bond interactions with the phosphate moiety [57] [PDB entry code: 1XON [57], molecular graphics created with YASARA (www.yasara.org) and PovRay (www.povray. org)]. 
20 1 Bioactive Macrocyclic Peptides and Peptide Mimics
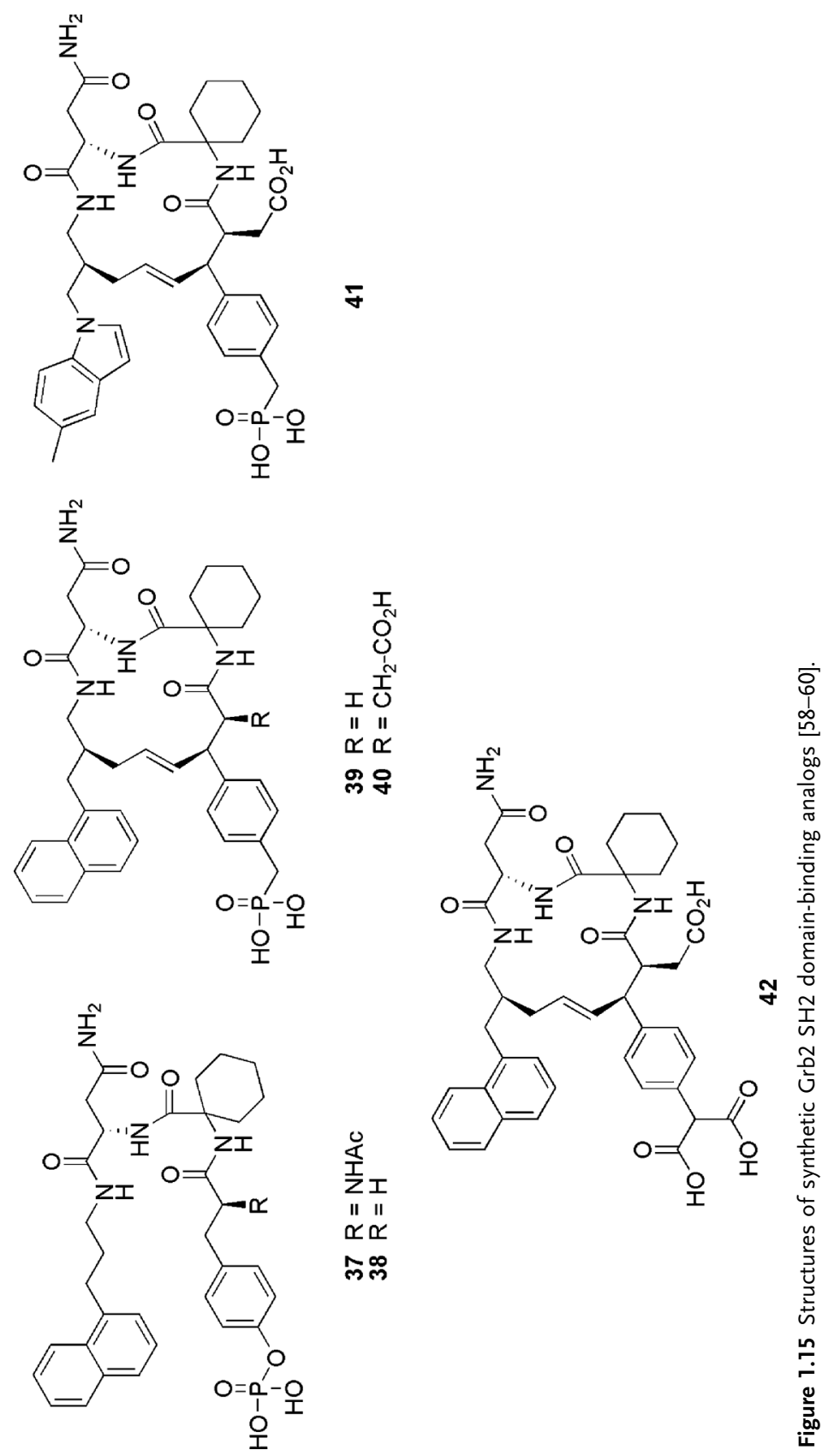
The recognition of phosphorylated peptides by $\mathrm{SH} 2$ domains depends on the phosphorylated residue. Specificity is determined by one or two nearby residues. Apart from the phosphotyrosine-specific recognition, SH2-domains can interact in different ways with other proteins [55]. This paragraph focuses on the interactions mediated by the conventional phosphopeptide recognition region. (The Grb2 SH2 domain plays a crucial role in the Ras signal transduction pathway, which is an important regulator of cell growth and differentiation.) Although most SH2 domains bind their phosphorylated peptide ligands in an extended, $\beta$-strandlike conformation, the Grb2 SH2 domain binds the natural ligand in a type I $\beta$ turn conformation [58]. High-affinity binding and recognition processes are mediated by the pTyr-Xaa-Asn motif. In tripeptide 37 (Figure 1.15), the amino acid at the second position is a 1-aminocyclohexanecarboxylic acid residue, which induces a $\beta$-turn conformation. This results in a high binding affinity of the peptide for the Grb2 SH2 domain. Removal of the acetylated amino functionality of the pTyr residue (compound 38, Figure 1.15) led to a 100-fold lower affinity, but cyclization restored this loss. However, in an intracellular assay, the cyclic peptide without $\alpha$ substitution (compound 39, Figure 1.15) was markedly less active than the linear peptide with this substitution [58]. A $K_{\mathrm{D}}$ value of $75 \mathrm{pM}$ was reported when the naphthyl group was replaced by a 5-methylindole and the $\alpha$ substitution was restored (compound 41, Figure 1.15). In cell assays, the compound was an effective inhibitor of mitosis in breast cancer cell culture [59].

Cyclization of peptides containing phosphate group mimics (42) increased binding affinities about five-fold in ELISA assays compared to their linear equivalents [60]. However, one should not consider cyclization as a panacea. Recently, we found, for example, that cyclization by ring-closing metathesis of a phosphopeptide interacting with the Grb2 SH2 domain did not give rise to improvement of binding affinity (Figure 1.16) [61].
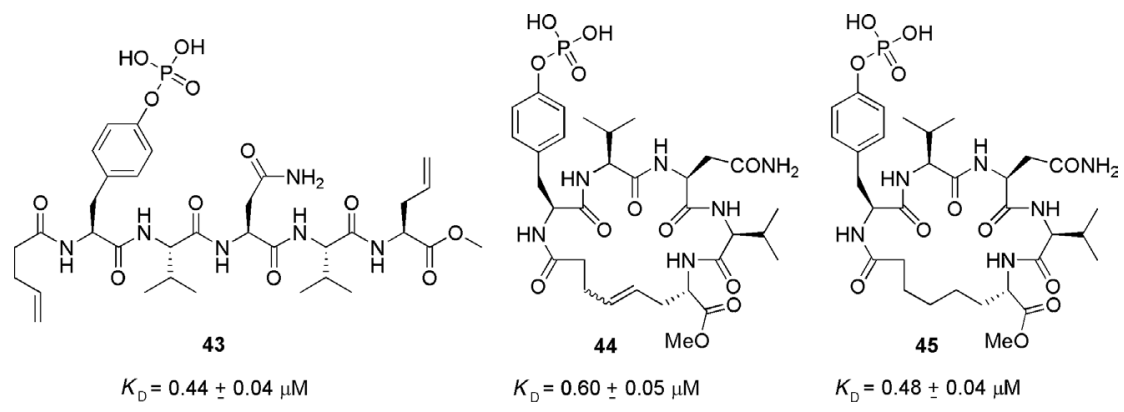

Figure 1.16 Linear phosphopeptide 43 and cyclic phosphopeptide ligands $\mathbf{4 4}$ and $\mathbf{4 5}$ obtained by ring-closing metathesis showing virtually no difference in affinity for the $\mathrm{Grb} 2 \mathrm{SH} 2$ domain as measured by a surface plasmon resonance assay [61]. 


\section{Conclusions}

The very limited number of bioactive (macro)cyclic peptides and peptide mimics for which molecular details of the interactions with targets are known stands in striking contrast to the vast and still increasing number of bioactive cyclic peptides. This calls for approaches to the elucidation of molecular mechanisms of interaction and target identification, since the biological activity of many of those peptides is extremely interesting, varying from antibiotic or anti-cancer activity to epigenetic behavior, or activity in signal transduction mechanisms. The studies could form a basis for the design and development of new generations of bioactive compounds also capable of interacting with large surfaces involved in many important protein-protein interactions. In this respect, macrocyclic peptide structures are particularly interesting because, in addition to the possibility of offering a large surface, the amino acid residues of which they are composed can offer a large diversity of functionalities for interaction. Since, in principle, there are no limitations to the preparation of macrocyclic peptide molecular constructs, there are plenty of opportunities for design and synthesis in the promising bio-supramolecular chemistry area.

\section{4}

\section{Experimental: Selected Procedures}

\subsection{1}

\section{Synthesis of Bicyclic Peptide 9: an Alkene-bridged Mimic of the Vancomycin C-D-E Cavity}

The original synthesis of this compound was described in Ref. [20]. The linear pentapeptide precursor, $N^{\alpha}$-(tert-butyloxycarbonyl)-seryl(allyl)-D-alanyl- $R, S$-4-hydroxy-3,5bisallyl-phenylglycyl-D-leucyl-serine(allyl) methyl amide $(20 \mathrm{mg}, 0.025 \mathrm{mmol}$ ) was dissolved in a mixture of TCE $(12 \mathrm{~mL})$ and DMF $(0.5 \mathrm{~mL})$. This solution was purged with $\mathrm{N}_{2}$ and heated to $80^{\circ} \mathrm{C}$ followed by the addition of the $2^{\text {nd }}$ generation Grubbs' catalyst $(21 \mathrm{mg}, 0.025 \mathrm{mmol}$ ). After $10 \mathrm{~min}$ the reaction was complete according to TLC and ES-MS. Subsequently, the solvent was removed under reduced pressure and the residue was purified by column chromatography (eluent: $\mathrm{CH}_{2} \mathrm{Cl}_{2} \rightarrow \mathrm{CH}_{2} \mathrm{Cl}_{2}$ / $\mathrm{MeOH} 95: 5, v / v)$. The tandem ring-closed pentapeptide 9 was obtained as a slightly brownish solid in $67 \%$ yield $(13 \mathrm{mg})$. HPLC analysis showed that the product was $92 \%$ pure (based on the diastereomers). HR-MS calcd. for $[M+\mathrm{H}]^{+}: \mathrm{C}_{37} \mathrm{H}_{54} \mathrm{~N}_{6} \mathrm{O}_{10}^{+}$: 743.3979; found $m / z[M+\mathrm{H}]^{+}: 743.3969$.

\section{4 .2}

\section{Synthesis of Cyclic Peptide 14: an Alkyne-bridged Mimic of the Nisin A-Ring Fragment}

The original synthesis of this compound was described in Ref. [36b]. The ringclosing alkyne metathesis reaction was carried out under argon in flame-dried 
glassware using Schlenk techniques. The linear pentapeptide precursor, $N^{\alpha}$-(tertbutyloxycarbonyl)-(2-butyne-glycyl)-isoleucyl-alanyl-leucyl-(2-butyne-glycine) methyl ester $(46 \mathrm{mg}, 0.070 \mathrm{mmol}$ ) was dissolved in dry toluene $(200 \mathrm{~mL})$, and the tungstenalkylidyne catalyst $\left({ }^{t} \mathrm{BuO}\right){ }_{3} \mathrm{~W} \equiv \mathrm{C}^{t} \mathrm{Bu}(4 \mathrm{mg}, 9 \mu \mathrm{mol})$ was added. The obtained reaction mixture was heated to $80^{\circ} \mathrm{C}$ and stirred for $2 \mathrm{~h}$. The reaction was monitored by TLC until no changes in product distribution could be observed. Then, $\mathrm{H}_{2} \mathrm{O}(1 \mathrm{~mL})$ was added to quench the catalyst, and the solvent was removed by evaporation. The residue was purified by column chromatography with $\mathrm{CH}_{2} \mathrm{Cl}_{2} / \mathrm{MeOH}$ 97.5:2.5, v/v as the eluent. Cyclic pentapeptide 14 was obtained as an off-white powder in $42 \%$ yield (18 mg). HR-MS calcd for $[M+\mathrm{H}]^{+}: \mathrm{C}_{29} \mathrm{H}_{47} \mathrm{~N}_{5} \mathrm{O}_{8}^{+}: 616.33218$; found $\mathrm{m} / z$ $[M+\mathrm{H}]^{+}: 616.33223$.

\section{Abbreviations}

$\begin{array}{ll}\text { Abu } & \text { 2-aminobutyric acid } \\ \text { Ac } & \text { acetyl } \\ \text { Ala } & \text { alanine (A) } \\ \text { Arg } & \text { arginine (R) } \\ \text { kArg } & \alpha \text {-ketoarginine; } \alpha \text {-oxo-L- } \beta \text {-homoarginine } \\ \text { Asn } & \text { asparagine (N) } \\ \text { Asp } & \text { aspartic acid (D) } \\ \text { Boc } & \text { tert-butyloxycarbonyl } \\ \text { BOP } & \text { benzotriazol-1-yloxy-tris(dimethylamino)phosphonium } \\ & \text { hexafluorophosphate } \\ \text { Bn } & \text { benzyl } \\ { }^{i} \text { Bu } & \text { iso-butyl } \\ { }^{t} \text { Bu } & \text { tert-butyl } \\ \text { Cbz } & \text { carbobenzyloxy } \\ \text { CN } & \text { calcineurin } \\ \text { CsA } & \text { cyclosporin A } \\ \text { CtA } & \text { cyclotheonamide A } \\ \text { CtB } & \text { cyclotheonamide B } \\ \text { CyPA } & \text { cyclophilin A } \\ \text { Dha } & \text { dehydroalanine } \\ \text { Dhb } & \text { (Z)-dehydrobutyrine } \\ \text { DIPEA } & \text { diisopropylethylamine } \\ \text { DMAP } & \text { 4-dimethylaminopyridine } \\ \text { DMF } & \text { dimethylformamide } \\ \text { Dpr } & \text { 2,3-diaminopropionic acid } \\ \text { ELISA } & \text { enzyme linked immunosorbent assay } \\ \text { ES-MS } & \text { electrospray mass spectrometry } \\ \text { Fmoc } & \text { 9-fluorenylmethyloxycarbonyl } \\ \text { For } & \text { formyl } \\ \text { GlcNAc } & N \text {-acetyl glucosamine } \\ & \end{array}$


Gly

Grb2

glycine $(\mathrm{G})$

His histidine $(\mathrm{H})$ growth factor receptor-bound protein 2

HPLC high-pressure liquid chromatography

HR-MS high-resolution mass spectrometry

Ile isoleucine (I)

Leu leucine (L)

Lys lysine (K)

Me methyl

Met methionine (M)

MRSA methicillin resistant Staphylococcus aureus

Mtr 4-methoxy-2,3,6-trimethylbenzenesulfonyl

MurNAc $\quad N$-acetyl muramic acid

NFAT nuclear factor of activated T-cells

NMR nuclear magnetic resonance

Pac phenacyl

Phe phenylalanine $(\mathrm{F})$

Pht phthaloyl

Pro proline $(\mathrm{P})$

RCAM ring-closing alkyne metathesis

RCM ring-closing metathesis

SAR structure-activity relationship

SASRIN 2-amino-4-alkoxybenzylalcohol resin

SEM 2-(trimethylsilyl)ethoxymethyl

Ser serine (S)

SH2 Src homology 2

TBDMS tert-butyl dimethyl silyl

TCE 1,1,2-trichloroethane

TFA trifluoroacetic acid

Thr threonine (T)

TLC thin layer chromatography

Tos tosyl

Trp tryptophan (W)

Trt trityl

p TsOH para-toluenesulfonic acid

Tyr tyrosine $(\mathrm{Y})$

vTyr vinylogous tyrosine; L-tyrosine-derived $\alpha, \beta$-unsaturated $\gamma$-amino acid

Val valine (V)

VanA resistance to vancomycin of type $A$

VanB resistance to vancomycin of type B

VanC resistance to vancomycin of type $C$

Xaa unspecified amino acid residue 


\section{References}

1 (a) Boger, D.L. (2001) Med. Res. Rev., 21 (5), 356-381; (b) Nicolaou, K.C., Boddy, C.N.C., Bräse, S. and Winssinger, N. (1999) Angew. Chem., 111, 2230-2287. Angew. Chem. Int. Ed., 38, 2096-2152; (c) Rao, A.V.R., Gurjar, M.K., Reddy, K.L. and Rao, A.S. (1995) Chem. Rev., 95, 2135-2167.

2 Chatterjee, C., Paul, M., Xie, L. and van der Donk, W.A. (2005) Chem. Rev., 105, 633-684.

3 Haubner, R., Finsinger, D. and Kessler, H. (1997) Angew. Chem., 109, 1440-1456; Angew. Chem. Int. Ed., 36, 1374-1389.

4 Rüegger, A., Kuhn, M., Lichti, H., Loosli, H.-R., Huguenin, R., Quiquerez, C. and von Wartburg, A. (1976) Helv. Chim. Acta, 59, 1075-1092.

5 Fusetani, N., Matsunaga, S., Matsumoto, H. and Takebayashi, Y. (1990) J. Am. Chem. Soc., 112, 7053-7054.

6 Froideveaux, S. and Eberle, A.N. (2002) Biopolymers (Peptide Science), 66, 161-183.

7 X-ray structure of octreotide: Pohl, E., Heine, A., Sheldrick, G.M., Dauter, Z., Wilson, K.S., Kallen, J., Huber, W. and Pfäffli, P.J. (1995) Acta Crystallogr., Sect. D, 51, 48-59.

8 Rohl, C.A., Chakrabartty, A. and Baldwin, R.L. (1996) Protein Science, 5, 2623-2637.

9 (a) Benfield, A.P., Teresk, M.G., Plake, H.R., DeLorbe, J.E., Millspaugh, L.E. and Martin, S.F. (2006) Angew. Chem., 118, 6984-6989; Angew. Chem. Int. Ed., 45, 6830-6835; (b) de Mol, N.J., Catalina, M.I., Dekker, F.J., Fischer, M.J.E., Heck, A.J.R. and Liskamp, R.M.J. (2005) ChemBioChem., 6, 2261-2270.

10 Knox, J.R. and Pratt, R.F. (1990) Antimicrob. Agents Chemother., 34, 1342-1347.

11 Mackay, J.P., Gerhard, U., Beauregard, D.A., Maplestone, R.A. and Williams, D. H. (1994) J. Am. Chem. Soc., 116, 45734580 .
12 Williams, D.H., Maguire, A.J., Tsuzuki, W. and Westwell, M.S. (1998) Science, 280, 711-714.

13 Mackay, J.P., Gerhard, U., Beauregard, D.A., Westwell, M.S., Searle, M.S. and Williams, D.H. (1994) J. Am. Chem. Soc., 116, 4581-4590.

14 (a) Süssmuth, R.D. (2002) ChemBioChem, 3, 295-298; (b) Walsh, C. T., Fisher, S.L., Park, I.-S., Prahalad, M. and Wu, Z. (1996) Chem. Biol., 3, 21-28.

15 (a) Printsevskaya, S.S., Pavlov, A.Y., Olsufyeva, E.N., Mirchnink, E.P., Isakova, E.B., Reznikova, M.I., Goldman, R.C., Branstrom, A.A., Baizman, E.R., Longley, C.B., Sztaricskai, F., Batta, G. and Preobrazhenskaya, M.N. (2002) J. Med. Chem., 45, 1340-1347; (b) Crowley, B.M., Mori, Y., McComas, C.C., Tang, D. and Boger, D.L. (2004) J. Am. Chem. Soc., 126, 4310-4317; (c) Boger, D.L., Kim, S. H., Mori, Y., Weng, J.-H., Rogel, O., Castle, S.L. and McAtee, J.J. (2001) J. Am. Chem. Soc., 123, 1862-1871.

$16 \mathrm{Xu}, \mathrm{R} .$, Greiveldinger, G., Marenus, L.E., Cooper, A. and Ellman, J.A. (1999) J. Am. Chem. Soc., 121, 4898-4899.

17 Bois-Choussy, M., Neuville, L., Beugelmans, R. and Zhu, J. (1996) J. Org. Chem., 61, 9309-9322.

18 Arnusch, C.J. and Pieters, R.J. (2003) Eur. J. Org. Chem., 3131-3138.

19 ten Brink, H.T., Rijkers, D.T.S. and Liskamp, R.M.J. (2006) J. Org. Chem., 71, 1817-1824.

20 ten Brink H.T., Rijkers D.T.S., Kemmink J., Hilbers H.W. and Liskamp R.M.J. (2004) Org. Biomol. Chem., 2, 2658-2663.

21 Gross, E. and Morell, J.L. (1971) J. Am. Chem. Soc., 93, 4634-4635.

22 Ramseier, H.R. (1960) Arch. Microbiol., 37, 57-94.

23 Ruhr, E. and Sahl, H.-G. (1985) Antimicrob. Agents Chemother., 27, 841-845. 
24 Linnett, P.E. and Strominger, J.L. (1973) Antimicrob. Agents Chemother., 4, 231-236.

25 Reisinger, P., Seidel, H., Tschesche, H. and Hammes, W.P. (1980) Arch. Microbiol., 127, 187-193.

26 Breukink, E., Wiedemann, I., van Kraaij, C., Kuipers, O.P., Sahl, H.-G. and de Kruijff, B. (1999) Science, 286, 2361-2364.

27 Hoffmann, A., Pag, U., Wiedemann, I. and Sahl, H.-G. (2001) Il Farmaco, 57, 685-691.

28 Brötz, H., Josten, M., Wiedemann, I., Schneider, U., Götz, F., Bierbaum, G. and Sahl, H.-G. (1998) Mol. Microbiol., 30, 317-327.

29 Chan, W.C., Leyland, M., Clark, J., Dodd, H.M., Lian, L.-Y., Gasson, M.J., Bycroft, B.W. and Roberts, G.C.K. (1996) FEBS Lett., 390, 129-132.

30 Wiedemann, I., Breukink, E., van Kraaij, C., Kuipers, O.P., Bierbaum, G., de Kruijff, B. and Sahl, H.-G. (2001) J. Biol. Chem., 276, 1772-1779.

$31 \mathrm{Hsu}$, S.-T.D., Breukink, E., de Kruijff, B., Kaptein, R., Bonvin, A.M.J.J. and van Nuland, N.A.J. (2002) Biochemistry, 41, 7670-7676.

$32 \mathrm{Hsu}$, S.-T.D., Breukink, E., Tischenko, E., Lutters, M.A.G., de Kruijff, B., Kaptein, R., Bonvin, A.M.J.J. and van Nuland, N.A.J. (2004) Nat. Struct. Mol. Biol., 11, 963-967.

33 van Heusden, H.E., de Kruijff, B. and Breukink, E. (2002) Biochemistry, 41, 12171-12178.

34 Hasper, H.E., de Kruijff, B. and Breukink, E. (2004) Biochemistry, 43, 11567-11575.

35 Hasper, H.E., Kramer, N.E., Smith, J.L., Hillman, J.D., Zachariah, C., Kuipers, O. P., de Kruijff, B. and Breukink, E. (2006) Science, 313, 1636-1637.

36 (a) Ghalit, N., Rijkers, D.T.S., Kemmink, J., Versluis, C. and Liskamp, R.M.J. (2005) Chem. Commun., 192-194; (b) Ghalit, N., Poot, A.J., Fürstner, A. and Rijkers, D.T.S. and Liskamp, R.M.J. (2005) Org. Lett., 7, 2961-2964; (c)
Ghalit, N., Rijkers, D.T.S. and Liskamp, R.M.J. (2006) J. Mol. Catal. A: Chem., 254, 68-77; (d) Ghalit, N., Kemmink, J., Hilbers, H.W., Versluis, C., Rijkers, D.T. S. and Liskamp, R.M.J. (2007) Org. Biomol. Chem., 5, 924-934.

37 For a solid phase synthesis: Angell, Y.M., Thomas, T.L., Flentke, G.R. and Rich, D. H. (1995) J. Am. Chem. Soc., 117, 7279-7280.

38 Huai, Q., Kim, H.-Y., Liu, Y., Zhao, Y., Mondragon, A., Liu, J.O. and Ke, H. (2002) Proc. Natl. Acad. Sci. U.S.A., 99, 12037-12042.

39 For a review on sponge peptides: Fusetani, N. and Matsunaga, S. (1993) Chem. Rev., 93, 1793-1806.

40 Since the original paper by Fusetani and Matsunaga [39], Hagihara and Schreiber reassigned the stereochemistry of the vinylogous tyrosine- and $\alpha$-ketoarginine residue to be of the $S$-configuration Hagihara, M. and Schreiber, S.L. (1992) J. Am. Chem. Soc., 114, 6570-6571.

41 (a) Maryanoff, B.E., Qiu, X., Padmanabhan, K.P., Tulinsky, A., Almond, H.R. Jr., Andrade-Gordon, P., Greco, M.N., Kauffman, J.A., Nicolaou, K. C., Liu, A., Brungs, P.H. and Fusetani, N. (1993) Proc. Natl. Acad. Sci. U.S.A., 90, 8048-8052; (b) Lee, A.Y., Hagihara, M., Karmacharya, R., Albers, M.W., Schreiber, S.L. and Clardy, J. (1993) J. Am. Chem. Soc., 115, 12619-12620; (c) Ganesh, V., Lee, A. Y., Clardy, J. and Tulinsky, A. (1996) Protein Sci., 5, 825-835.

42 Bode, W., Mayr, I., Baumann, U., Huber, R., Stone, S.R. and Hofsteenge, J. (1989) EMBO J., 8, 3467-3475.

43 (a) Wipf, P. and Kim, H. (1993) J. Org. Chem., 58, 5592-5594; (b) Deng, J., Hamada, Y., Shioiri, T., Matsunaga, S. and Fusetani, N. (1994) Angew. Chem., 106, 1811-1813; Angew. Chem. Int. Ed. Engl., 33, 1729-1731; (c) Maryanoff, B.E., Greco, M.N., Zhang, H.-C., AndradeGordon, P., Kauffman, J.A., Nicolaou, K. C., Liu, A. and Brungs, P.H. (1995) J. Am. Chem. Soc., 117, 1225-1239; (d) 
Bastiaans, H.H.M., van der Baan, J.L. and Ottenheijm, H.C.J. (1997) J. Org. Chem., 62, 3880-3889.

44 (a) Maryanoff, B.E., Zhang, H.-C., Greco, M.N., Glover, K.A., Kauffman, J.A. and Andrade-Gordon, P. (1995) Bioorg. Med. Chem., 3, 1025-1038; (b) Nakao, Y., Matsunaga, S. and Fusetani, N. (1995) Bioorg. Med. Chem., 3, 1115-1122.

45 For a review see: Gustafsson, D., Bylund, R., Antonsson, T., Nilsson, I., Nyström, J.-E., Eriksson, U., Bredberg, U. and Teger-Nilsson, A.-C. (2004) Nat. Rev. Drug Discovery, 3, 649-659.

46 (a) Plow, E.F., Haas, T.A., Zhang, L., Loftus, J. Smith, J.W. (2000) J. Chem. Biol., 275, 21785-21788; (b) Gottschalk, K.-E. and Kessler, H. (2002) Angew. Chem., 114, 3919-3927; Angew. Chem. Int. Ed., 41, 3767-3774.

47 (a) Hynes, R.O. (1992) Cell, 69, 11-25; (b) Brooks, P.C., Clark, R.A. and Cheresh, D.A. (1994) Science, 264, 569-571; (c) Hynes, R.O. (2002) Nat. Med., 8, 918-921.

48 Xiong, J.-P., Stehle, T., Zhang, R., Joachimiak, A., Frech, M., Goodman, S. L. and Arnaout, M.A. (2002) Science, 296, 151-155.

49 Brooks, P.C., Montgomery, A.M.P., Rosenfeld, M., Reisfeld, R.A., Hu, T., Klier, G. and Cheresh, D.A. (1994) Cell, 79, 1157-1164.

50 Hood, J.D., Bednarski, M., Frausto, R., Guccione, S., Reisfeld, R.A., Xiang, R. and Cheresh, D.A. (2002) Science, 296, 2404-2407.

51 Gurrath, M., Müller, G., Kessler, H., Aumailley, M. and Timpl, R. (1992) Eur. J. Biochem., 210, 911-921.

52 Haubner, R., Gratias, R., Diefenbach, B., Goodman, S.L., Jonczyk, A. and Kessler, H. (1996) J. Am. Chem. Soc., 118, 7461-7472.

53 Haubner, R., Wester, H.-J., Reuning, U., Senekowitsch-Schmidtke, R., Diefenbach, B., Kessler, H., Stöcklin, G. and Schwaiger, M. (1999) J. Nucl. Med., 40, 1061-1071.
54 (a) For the chemical synthesis of Echistatin, see: Garsky, V.M., Lumma, P.K., Freidinger, R.M., Pitzenberger, S.M., Randall, W.C., Veber, D.F., Gould, R.J. and Friedman, P.A. (1989) Proc. Natl. Acad. Sci. U.S.A., 86, 4022-4026; (b) For the structural elucidation by NMR, see: Saudek, V., Atkinson, R.A. and Pelton, J.T. (1991) Biochemistry, 30, 7369-7372.

55 (a) Liu, B.A., Jablonowski, K., Raina, M., Arcé, M., Pawson, T. and Nash, P.D. (2006) Mol. Cell, 22, 851-868; (b) Machida, K. and Mayer, B.J. (2005) Biochim. Biophys. Acta, 1747, 1-25.

56 (a) Overduin, M., Rios, C.B., Mayer, B.J., Baltimore, D. and Cowburn, D. (1992) Cell, 70, 697-704; (b) Waksman, G., Kominos, D., Robertson, S.C., Pant, N., Baltimore, D., Birge, R.B., Cowburn, D., Hanafusa, H., Mayer, B.J., Overduin, M., Resh, M.D., Rios, C.B., Silverman, L. and Kuriyan, J. (1992) Nature, 358, 646-653; (c) Booker, G.W., Breeze, A.L., Downing, A.K., Panayotou, G., Gout, I., Waterfield, M.D. and Campbell, I.D. (1992) Nature, 358, 684-687.

57 Ogura, K., Shiga, T., Yuzawa, S., Yokochi, M., Burke, T.R. and Inagaki, F., unpublished results: PDB access code: $1 \mathrm{X} 0 \mathrm{~N}$.

58 Gao, Y., Voigt, J., Wu, J.X., Yang, D. and Burke, T.R. Jr. (2001) Bioorg. Med. Chem. Lett., 11, 1889-1892.

59 Shi, Z.-D., Lee, K., Liu, H., Zhang, M., Roberts, L.R., Worthy, K.M., Fivash, M. J., Fisher, R.J., Yang, D. and Burke, T.R. Jr. (2003) Biochem. Biophys. Res. Commun., 310, 378-383.

60 Shi, Z.-D., Wei, C.-Q., Lee, K., Liu, H., Zhang, M., Araki, T., Roberts, L.R., Worthy, K.M., Fisher, R.J., Neel, B.G., Kelley, J.A., Yang, D. and Burke, T.R. Jr. (2004) J. Med. Chem., 47, 2166-2169.

61 Dekker, F.J., de Mol, N.J., Fischer, M.J. E., Kemmink, J. and Liskamp, R.M.J. (2003) Org. Biomol. Chem., 1, 3297-3303. 
